Article

\title{
Detailed Geophysical Mapping and Hydrogeological Characterisation of the Subsurface for Optimal Placement of Infiltration-Based Sustainable Urban Drainage Systems
}

\author{
Theis Raaschou Andersen $(\mathbb{D}$ \\ Research Centre for Built Environment, Energy, Water and Climate, VIA University College, 8700 Horsens, \\ Denmark; Thra@via.dk; Tel.: +45-8755-4295
}

Received: 29 September 2020; Accepted: 4 November 2020; Published: 8 November 2020

\begin{abstract}
The continuous growth of cities in combination with future climate changes present urban planners with significant challenges, as traditional urban sewer systems are typically designed for the present climate. An easy and economically feasible way to mitigate this is to introduce a Sustainable Urban Drainage System (SUDS) in the urban area. However, the lack of knowledge about the geological and hydrogeological setting hampers the use of SUDS. In this study, 1315 ha of high-density electromagnetic (DUALEM-421S) data, detailed lithological soil descriptions of 614 boreholes, 153 infiltration tests and 250 in situ vane tests from 32 different sites in the Central Denmark Region were utilised to find quantitative and qualitative regional relationships between the resistivity and the lithology, the percolation rates and the undrained shear strength of cohesive soils at a depth of 1 meter below ground surface ( $\mathrm{m} \mathrm{bgs}$ ). The qualitative tests enable a translation from resistivity to lithology as well as a translation from lithology to percolation rates with moderate to high certainty. The regional cut-off value separating sand-dominated deposits from clay-dominated deposits is found to be between 80 to $100 \Omega \mathrm{m}$. The regional median percolation rates for sand and clay till is found to be $9.9 \times 10^{-5} \mathrm{~m} / \mathrm{s}$ and $2.6 \times 10^{-5} \mathrm{~m} / \mathrm{s}$, respectively. The quantitative results derived from a simple linear regression analysis of resistivity and percolation rates and resistivity and undrained shear strength of cohesive soils are found to have a very weak relationship on a regional scale implying that in reality no meaningful relationships can be established. The regional qualitative results have been tested on a case study area. The case study illustrates that site-specific investigations are necessary when using geophysical mapping to directly estimate lithology, percolation rates and undrained shear strength of cohesive soils due to the differences in soil properties and the surrounding environment from site to site. This study further illustrates that geophysical mapping in combination with lithological descriptions, infiltration tests and groundwater levels yield the basis for the construction of detailed planning maps showing the most suitable locations for infiltration. These maps provide valuable information for city planners about which areas may preclude the establishment of infiltration-based SUDS.
\end{abstract}

Keywords: geophysical mapping; DUALEM-421S; SUDS; infiltration tests; planning map; hydrogeological characterisation

\section{Introduction}

The United Nations estimate that in $2050,68 \%$ of the world's population of approximately 10 billion people will reside in urban areas [1]. The continuous growth of cities in combination with future climate changes present authorities with significant challenges. In Denmark, climate models estimate that future climate changes will cause an increase in the overall amount of precipitation along 
with a changing precipitation pattern where more frequent cloudbursts are expected to occur [2,3]. As traditional urban sewer systems are designed for the present climate, the new precipitation pattern will increase the frequency of flooding in urban areas, which will hamper and destroy infrastructure, buildings and the environment [4]. According to the European Environment Agency, an economic loss of approximately 453 billion euro can be assigned to weather and climate-related extremes in the period from 1980 to 2017 [5]. Therefore, one of the most significant challenges for urban planners is to ensure stable disposal of waste and surface water. Consequently, over the last 20 years, there has been an increasing focus on using SUDS in cities. Implementing SUDS in surface water management plans has many benefits. Studies show that the handling of surface water using SUDS is less expensive than traditional handling using sewers [6-10]. In addition, the SUDS enable urban planners to use surface water as a resource instead of a problem, e.g., surface water can be used to make cities green, counteract urban heat effect as well as restore the hydraulic water cycle in urban areas [11-13].

One of the approaches used in Denmark is infiltration-based SUDS, such as ponds, swales, rain gardens, soakaways and infiltration trenches. The primary reason for this is that infiltration-based SUDSs are cost-effective and easy to construct, compared to many other SUDS solutions. In order to find the most suitable SUDS solution for a specific area, the ground conditions, such as infiltration capacity and groundwater conditions must be known in detail, as a site may restrict or preclude a particular SUDS solution. This is especially the case in former glaciated areas, as many glacial deposits often are highly heterogeneous, and thus, their hydrological conditions can likewise be highly variable [14,15]. The heterogeneity is both present within the individual units, e.g., sand lenses embodied in clay till, the presence of fractures, root holes and earthworm burrows [15] as well as between the units. To map both the internal heterogeneity as well as the overall heterogeneity of the subsurface, very detailed studies are required, which are typically time consuming and therefore also very expensive.

Typically, the data available for urban planners when designing new urban developments is point information, such as drilling in combination with overall 2D geological maps showing, e.g., soil type, infiltration capacity, areal extent and the thickness of the individual units. This is useful for identifying overall suitable locations for infiltration but is unsuitable for describing the geological and hydrogeological conditions in sufficient detail for urban planners to be able to select the best SUDS solution [16]. The need for on-site data remains. Furthermore, drillings are invasive and costly, making them unsuitable to map large areas in detail. To compensate for the lack of dense data derived from boreholes, geophysical methods represent an efficient and non-invasive tool for mapping both urban and rural areas [17-24]. Multiple studies throughout the last decades have shown that an empirical correlation between resistivity and lithology exists [25-28]. This correlation depends on several factors, such as water saturation, clay content, clay type, soil compaction, pore water ion content and matrix resistivity [29]. Therefore, the same lithological unit can have a wide resistivity range [30,31], and thus, large-scale investigations have been conducted in Denmark in order to estimate the overall resistivity range for various lithologies. Barfod et al., [31] have made a national resistivity atlas of Denmark in grids spanning $10 \times 10 \mathrm{~km}$ in which lithological information from boreholes has been integrated with resistivity from various transient electromagnetic methods, thus creating resistivity histograms for selected lithologies (clay, sand and gravel). The resistivity atlas of Denmark was created for two layers; 12.5 to $25 \mathrm{~m}$ and 25 to $55 \mathrm{~m}$, respectively, and not for the near subsurface.

For near-surface investigations, electromagnetic induction (EMI) methods have proven to be very effective in successfully mapping the subsurface [32-35]. For instance, Frederiksen et al., [36] made a quantitative comparison of a 1000 ha coherent EMI data set and 125 boreholes showing that the EMI instrument DUALEM-421S is able to map the geology of the upper $6 \mathrm{~m}$ in a complex glacial environment.

To the author's knowledge, few Danish studies have tried to establish a quantitative and/or qualitative relationship between resistivity and infiltration capacity, lithology and geotechnical tests based on large-scale data sampling. Until now, only site-specific geophysical mapping has been used to investigate the best placement of SUDSs as well as their infiltration performance in Denmark $[37,38]$. 
Therefore, it would be advantageous if more generic similarities between geoelectric resistance, lithology, geotechnical in situ vane tests and infiltration capacity could be achieved covering larger areas. If such compilations can be established, it can help city planners make credible decisions based on as little data as possible and choose the right combination of data types in order to create reliable planning maps. With better knowledge, optimal SUDSs can be better chosen within each area and an over-or underestimation or at worst case - the completely wrong solution can be avoided.

The objective of this paper is to use high-density geophysical mapping in combination with borehole data, infiltration tests and geotechnical data to outline the benefits of geophysical mapping for improved fidelity of the geological and hydrogeological characterisation at $1 \mathrm{~m}$ below ground surface (bgs) which is typically the construction depth of vast infiltration-based SUDS solutions in Denmark, e.g., soakaways. Data from the Central Denmark Region has been collected from 2015 and onwards from 32 different locations, and it comprises 1315 ha of high-density electromagnetic (DUALEM-421S) data, detailed lithological soil descriptions of 614 boreholes, 153 infiltration tests and 250 in situ vane tests. The data will be quantitatively and qualitatively analysed, and possible relationships between resistivity and the main lithological description and infiltration capacity and geotechnical data will be evaluated. The results will be exemplified with one case study from Provstlund, Denmark, in order to demonstrate how detailed geophysical and hydrogeological information can yield maps of the infiltration potential of urban development areas.

\section{Materials and Methods}

\subsection{Study Locations}

In this study, 1315 ha of DUALEM-421S have been obtained from 32 different locations from the central part of Denmark (Figure 1 and Table 1). The vast majority of the sites are primarily agricultural, and the geophysical mapping has therefore been conducted outside the cropping season in either spring or autumn.

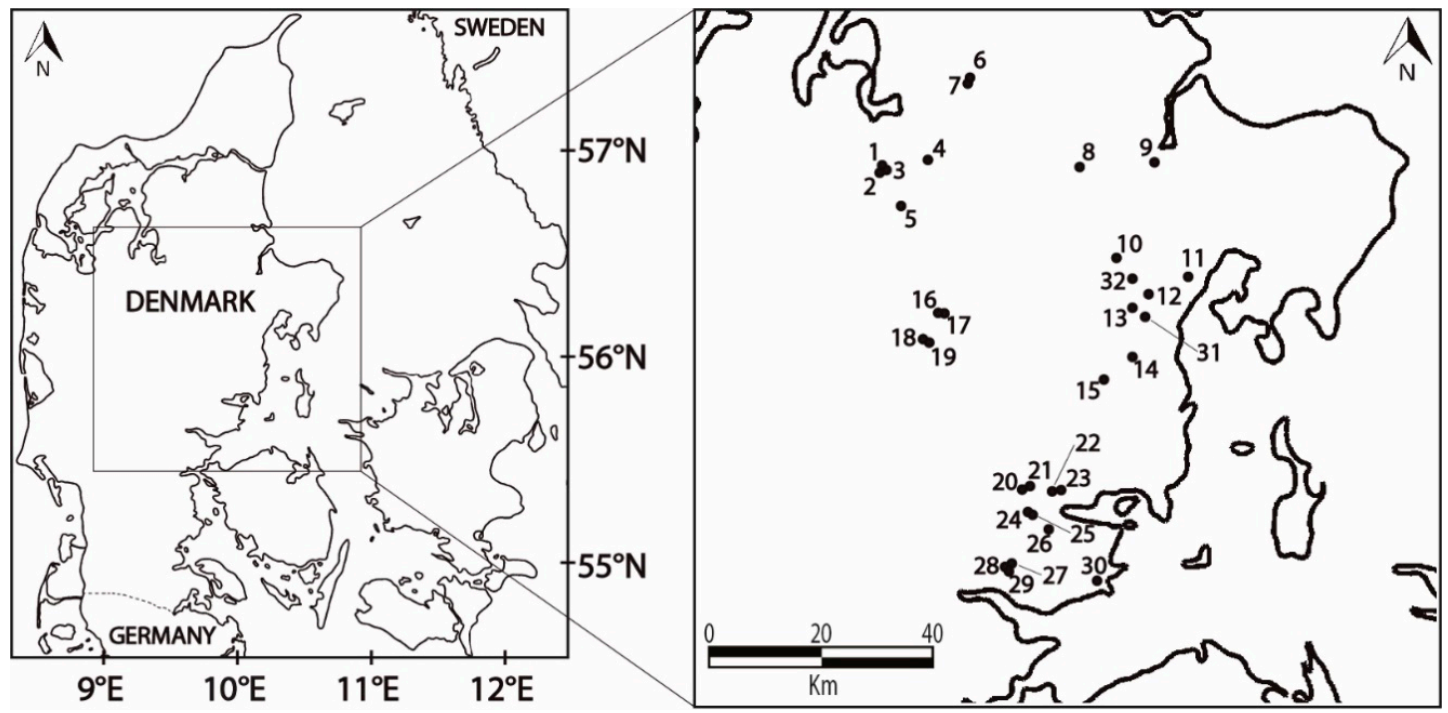

Figure 1. Overview map showing the location of the 32 sites. For names, specific locations and available data of each site, see Table 1.

Alongside the geophysical mapping, detailed lithological soil descriptions of a total of 614 boreholes, 153 infiltration tests and 250 in situ vane tests were obtained. As seen in Table 1, all the geophysical mapping sites held drillings, with the highest amount being at Provstlund and Østerhåb Vest. The highest number of infiltration tests was conducted at Nørrestrand Øst with 25, followed by Ørnstrup Møllevej and Hatting with 20. 
Table 1. Information on all the Investigated Sites.

\begin{tabular}{|c|c|c|c|c|c|c|}
\hline No. & Name & $\begin{array}{c}\text { Location } \\
\text { (UTM32E89) }\end{array}$ & $\begin{array}{l}\text { Geophysical } \\
\text { Mapping (Ha) }\end{array}$ & Drillings & $\begin{array}{l}\text { Infiltration } \\
\text { Tests }\end{array}$ & $\begin{array}{c}\text { In Situ Vane } \\
\text { Tests }\end{array}$ \\
\hline 1 & Vestbyen & 520650,6255950 & 219 & 24 & 7 & \\
\hline 2 & Viborg 4F3 & 520249,6254507 & 132 & 11 & 4 & \\
\hline 3 & Viborg 4F4P & 521524,6255114 & 11.6 & 4 & 2 & \\
\hline 4 & Taphede & 529380,6257010 & 221 & 21 & 4 & \\
\hline 5 & Almind & 524262,6248129 & 1.2 & 2 & 1 & \\
\hline 6 & Klejtrup E11 & 538680,6272919 & 1.8 & 2 & 1 & \\
\hline 7 & Klejtrup E12 & 538131,6271512 & 9.5 & 5 & & \\
\hline 8 & Svenstrup & 558371,6255606 & 11 & 4 & & \\
\hline 9 & Drastrup & 572599,6256509 & 23 & 8 & & \\
\hline 10 & Hinnerup & 565390,6238320 & 150 & 4 & & \\
\hline 11 & Gammel Kirkevej & 579049,6234795 & 3.8 & 7 & & 7 \\
\hline 12 & Lisbjerg & 571500,6231350 & 24 & 20 & & 12 \\
\hline 13 & Tilst & 568650,6228343 & 10 & 7 & & 4 \\
\hline 14 & Lemmingvej & 568390,6219499 & 15 & 12 & & 10 \\
\hline 15 & Hørning Syd & 562950,6215150 & 55 & 12 & & 2 \\
\hline 16 & $\begin{array}{c}\text { Astrid } \\
\text { Lindgrensvej }\end{array}$ & 531507,6227910 & 40 & 8 & & 6 \\
\hline 17 & Balle Bygade & 532336,6227859 & 4 & 4 & & \\
\hline 18 & Funder Skole & 528462,6222890 & 5.5 & 7 & & \\
\hline 19 & Funder & 529602,6222190 & 7 & 5 & 3 & \\
\hline 20 & Lund & 547340,6194190 & 36 & 19 & 16 & 8 \\
\hline 21 & Provstlund & 548810,6194830 & 27 & 161 & 18 & 46 \\
\hline 22 & Nørrestrand Vest & 553170,6193810 & 60 & 8 & 6 & \\
\hline 23 & Nørrestrand Øst & 554850,6194120 & 150 & 25 & 25 & \\
\hline 24 & Hatting & 548500,6189890 & 27 & 20 & 20 & 10 \\
\hline 25 & Østerhåb Vest & 549380,6189380 & 40 & 143 & 15 & 124 \\
\hline 26 & Ørnstrup Møllevej & 552474,6186625 & 17 & 20 & 20 & \\
\hline 27 & Constantiaparken & 545460,6180130 & 8.5 & 3 & 4 & \\
\hline 28 & Rugmarken & 544090,6179390 & 2.5 & 6 & 4 & 3 \\
\hline 29 & Silkavej & 544630,6178850 & 2.5 & 4 & 3 & \\
\hline 30 & Vejlevej & 561103,6175409 & 4.5 & 3 & & \\
\hline 31 & Marienlystvej & 570746,6227953 & 8 & 5 & & 4 \\
\hline 32 & Aarhusvej & 567723,6233531 & 40 & 30 & & 14 \\
\hline
\end{tabular}

All the study sites are located in the eastern part of Jutland which was covered by ice during the Weichselian glaciation [39]. The geology in all sites has the same overall lithological log. At the surface, approximately 0.5 to $1 \mathrm{~m}$ of topsoil/fillings is observed, followed by either glacial deposits, such as clay till or meltwater sand, or a 0.5 to $2 \mathrm{~m}$ thick section of postglacial sediments. The glacial sediments were deposited during the Late Weichselian glaciations spanning 23,000 to 17,000 years ago. The postglacial sediments were deposited in the Holocene period, beginning 11,700 years ago. As all the locations are inland, the postglacial sediments typically comprise clay, sand and peat and are present in lowlands and depressions. The groundwater level is monitored in the vast majority of the sites and is typically within the range of 1 to $5 \mathrm{~m}$ bgs.

\subsection{Data}

\subsubsection{Dualem-421S}

The geophysical mapping was conducted with the DUALEM-421S ground conductivity meter system (DUALEM Inc., Milton, ON, Canada) from 2015 to 2019. The individual investigations were conducted by various geophysical companies, all using the DUALEM-421S sensor and the same overall processing and inversion scheme. Therefore, the results are considered comparable. In total, approximately $1850 \mathrm{~km}$ of lines have been collected. For all investigations, the DUALEM-421S instrument was mounted on a nonmetallic sled and pulled at least $3 \mathrm{~m}$ behind a 4WD quad bike. The sled ensured smooth operation with minimum effects from pitch and roll. The sensor was 
located approximately $0.25 \mathrm{~m}$ above the ground surface. The DUALEM-421S sensor held six receiver coils arranged behind the transmitter coil in distances ranging from 1 to $4.1 \mathrm{~m}$, three horizontal coplaner (HCP) coils at 1, 2 and $4 \mathrm{~m}$ and three perpendicular-planer (PRP) coils at 1.1, 2.1 and $4.1 \mathrm{~m}$. The system operated at $9000 \mathrm{~Hz}$ with a maximum sampling rate of $10 \mathrm{~Hz}$, which provided approximately two samples per $1 \mathrm{~m}$ when the equipment was operated at a speed of $15-20 \mathrm{~km} / \mathrm{h}$. The systems simultaneously measured the electrical conductivity $(\mathrm{mS} / \mathrm{m})$ and the susceptibility at the six coil-configurations. Through geophysical inversion, the depth of investigation (DOI) was calculated. The DOI depends on the electrical characteristics of the subsurface [40]. In clay-dominated soils, the DOI is typically around $5 \mathrm{~m}$. In sand-dominated sediments, it can be up to $10 \mathrm{~m}$. The horizontal and vertical resolutions are around $1 \mathrm{~m}$ and $0.5 \mathrm{~m}$, respectively.

Data processing and inversion were carried out using the Aarhus Workbench software [41]. The measured conductivity of each of the six coil-configurations was imported and joined with the spatial position from the GPS. During the processing, the data sections were evaluated with overview maps including relevant information, e.g., the location of buried cables. Noisy and coupled data were removed in the processing. As the coupling effect was limited to 5-10 $\mathrm{m}$ from disturbing elements, usually only a minor portion, that is $<5 \%$ of the collected data was rejected from the dataset. Furthermore, the data was filtered using running mean filters in order to increase the signal to noise ratio.

The processed datasets were inverted using the spatially constrained inversion (SCI) scheme. SCI is a damped nonlinear least-squares inversion, where one-dimensional (1D) models are spatially constrained in a three-dimensional (3D) setup during inversion. This inversion approach enables the construction of a spatial inversion model that represents the optimal background for further use of the results [42]. Spatially constrained inversion (SCI) was applied for a smooth 14- or 15-layer model [42].

\subsubsection{Drillings}

In total, 614 drillings were compiled from the study areas. All the drillings were obtained from engineering companies and were characterised as high quality, as the drillings were made for geotechnical purposes. The drillings were made using a solid stem auger, providing the geologist with high-quality samples for soil description. The drillings were typically no more than 3-5 $\mathrm{m}$ deep. The vast majority of the drillings also includes groundwater head measurements, driller's logs, geological descriptions, in situ vane tests, drill depth and geographical coordinates.

\subsubsection{Infiltration Tests}

Two types of infiltration tests were conducted at the sites. The first type of infiltration test was based on the sieve analysis of sandy deposits. Hydraulic conductivity was found using the Danish standardisation DS 415 formula [43]

$$
\mathrm{K}=0.01 \times \mathrm{d}_{10}^{2}
$$

where $\mathrm{K}$ represents the hydraulic conductivity $(\mathrm{m} / \mathrm{s})$ and $\mathrm{d}_{10}$ is the $10 \%$ fractile from the effective grain size $(\mathrm{mm})$. This formula is valid for $\mathrm{d}_{10}$ larger than $0.1 \mathrm{~mm}$ and smaller than $3.0 \mathrm{~mm}$ and with a uniformity coefficient $\mathrm{U}\left(\mathrm{U}=\mathrm{d}_{60} / \mathrm{d}_{10}\right)$ less than 2.5 .

The remaining infiltration tests were simple falling head tests (percolation tests) conducted according to the recommendations from the Danish Technological Institute [44]. The test consists of a preparation phase and an execution phase. In the preparation phase, a hole spanning $0.5 \times 0.5 \mathrm{~m}$ is made with a depth under the top layer that is typically $0.5 \mathrm{~m}$ deep. Within this hole, the test hole spanning $0.25 \times 0.25 \mathrm{~m}$ with a depth between 0.25 and $0.5 \mathrm{~m}$ is made. The bottom elevation of the test hole should correspond to the bottom elevation of the proposed basin (infiltration surface). The bottom of the test hole is then covered with $2 \mathrm{~cm}$ of gravel and then presoaked. The presoaking should last at least $30 \mathrm{~min}$ and until the infiltration rate is constant, after which the execution phase can begin. Here, $20 \mathrm{~cm}$ of water is added to the test hole, and the water level is measured during the test period. 
The water head and the related time is measured for at least 15 min or until the test hole is empty. Based on the measured result, the percolation rate is calculated.

As the infiltration capacity derived from the sieve analysis represents the hydraulic conductivity for all three dimensions as well as the percolation rate from the falling head test, it was assumed that the two types of infiltration capacity tests could be collated. It should be noticed that the percolation rates derived from simple falling head tests are considered more inaccurate than, e.g., saturated hydraulic conductivity measured using a constant head test. Hence, comparing infiltration capacities from one investigation to another should only be done when the used infiltration test is known in detail.

\subsubsection{In Situ Vane Tests}

The vane shear test was used to find the undrained shear strength of cohesive soils. The test can be performed directly in the field and was conducted in accordance with the Danish Geotechnical Society-Field Committee (1999) guidelines [45]. In this study, the vane tests were conducted at the same depth as the infiltration tests or during the drillings at various drilling depths. The vane test was performed by gently lowering a four-blade stainless steel vane of approximately $10 \mathrm{~cm}$ into the ground. In order to find the peak of the undrained shear strength, the blade was slowly rotated ( 1 rotation per minute) until the maximum torque was reached, and the vane rotated due to the cylindrical surface fail of the soil by shear. To determine the remoulded undrained shear strength, the vane was rotated 10 times in the ground, and the torque was measured.

\section{Results and Discussion}

In the following section, the results of this study are presented and discussed. In order to perform a quantitative evaluation of the resistivities versus the infiltration capacity and the resistivities versus the undrained shear strength of cohesive soils, simple linear regression tests were conducted on the data. From the simple linear regression tests, we assessed whether a significant linear relationship between an independent variable $X$ and a dependent variable $Y$ exists. In our two tests, the dependent variable $\mathrm{Y}$ is either the percolation rate or the undrained shear strength of cohesive soils, and the independent variable $X$ is, in both tests, the resistivity.

Assuming a linear relationship between an independent variable $X$ and a dependent variable $Y$ exists, their relationship can be expressed as follows:

$$
Y_{i}=\alpha+\beta X_{i}
$$

where $\alpha$ is a constant, $\beta$ is the slope of the regression line, $X_{i}$ is the independent variable, and $Y_{i}$ is the dependent variable. In the simple linear regression test, we tested whether the slope of the regression line is significantly different from zero using the following hypothesis test:

$$
\begin{aligned}
& \text { Null Hypothesis: } \mathrm{H}_{0}: \beta=0 \\
& \text { Alternative Hypothesis: } \mathrm{H}_{\mathrm{a}}: \beta \neq 0
\end{aligned}
$$

In order to test the hypothesis, a linear regression t-test with $n-2$ degrees of freedom was conducted using a significance level of 0.05 . If the calculated $p$-value was less than the significance level, the null hypothesis was rejected. If the null hypothesis were rejected, we would be able to conclude that there is a significant relationship between the independent and dependent variables. Further information about the simple linear regression test is thoroughly described by, e.g., Blæsild and Granfeldt [46].

For qualitative evaluation of the lithologies versus resistivities and percolation rates, box plots were used. 


\subsection{Resistivities Versus Lithology}

In Figure 2 we show the minimum, maximum and median values as well as the Q1 and Q3 quartiles for resistivities of various lithologies at $1 \mathrm{~m}$ bgs. for all the investigated sites. The lithologies derived from the drillings are only included if more than $75 \%$ of the soil within the depth interval, that is from $0.5 \mathrm{~m}$ to $1.5 \mathrm{~m}$, had the same main lithology. The resistivity is obtained using the DUALEM-421S measurement nearest the drilling.

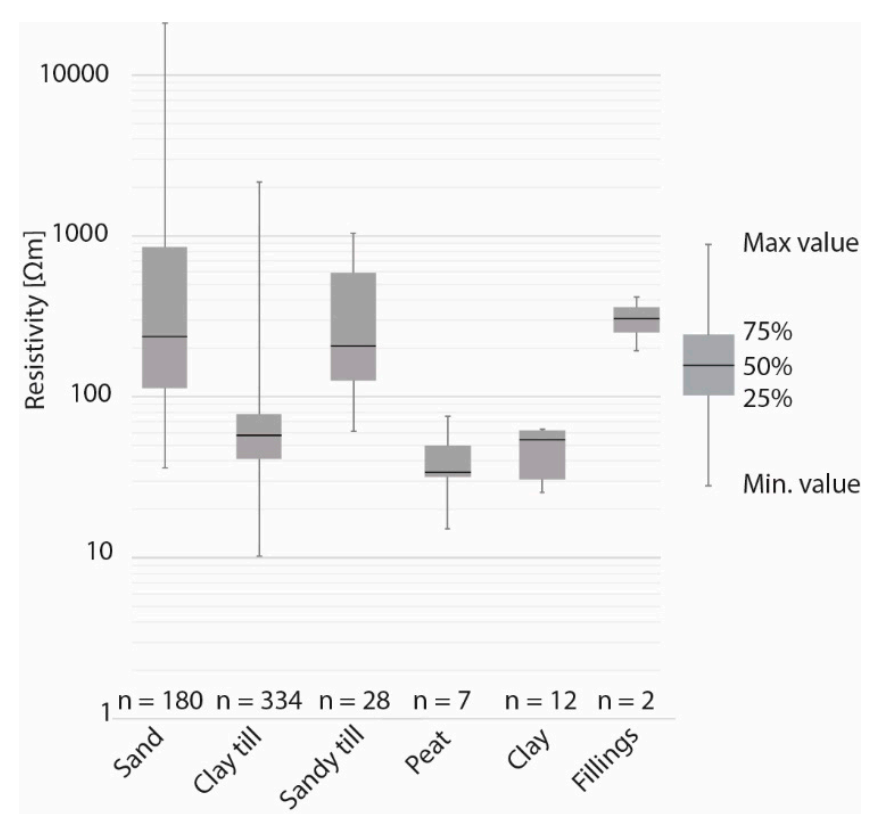

Figure 2. Box plot showing the resistivities of the different soil types observed within all the investigated areas. $\mathrm{N}$ represents the amount of measurements for each soil type.

As seen from the box plot, the units cannot, with high certainty, be distinguished from each other by their resistivities alone, as the maximum and minimum resistivity range in many situations are overlapping. However, the box plot shows that sand-dominated lithologies, such as sand, sandy till and fillings have higher resistivities relative to clay and organic-dominated lithologies, such as clay, clay till and peat/organic clay. The median resistivity for sand, sandy till and fillings are 229, 201 and $296 \Omega \mathrm{m}$, compared to the median resistivity for clay till, peat and clay, which are 56,33 and $30 \Omega \mathrm{m}$. For the sand-dominated deposits, the Q1 quartile for sand is the lowest with $110 \Omega \mathrm{m}$, and for the clay-dominated deposits, the Q3 quartile for clay till were the highest with $76 \Omega \mathrm{m}$. Hence, a cut-off value ranging from 80 to $100 \Omega \mathrm{m}$ can be used on a regional scale to separate the sand-dominated deposits from the clay-dominated deposits. These findings are in accordance with other Danish investigations. In Barfod et al., [31] and in Frederiksen et al., [36], a cut-off value of $80 \Omega \mathrm{m}$ was selected in order to separate the sand-dominated deposits from the clay-dominated deposits. From Figure 2, it is also observed that it is impossible to separate sand from sandy till and fillings based on their resistivity alone, as their median resistivity values only show minor variances. Likewise, it is not possible to distinguish between clay till, peat and clay on a regional scale.

As described in the Introduction, multiple studies have described an empirical correlation between resistivity and lithology [25-28]. This correlation depends on several factors, such as water saturation, clay content, clay type, soil compaction, pore water ion content and matrix resistivity [29]. For water-saturated clay-free porous media, such as sand, Archie's law [25] is valid, showing an empirical relationship of electrical conductivity to fluid (pore water ion content) and water content:

$$
\sigma_{b}=\frac{\sigma_{w}}{\mathrm{~F}}
$$


where $\sigma_{b}$ is the bulk conductivity of the formation, $\sigma_{w}$ is the fluid conductivity, and $\mathrm{F}$ is the formation factor. For clayey sediments, Archie's law is not valid, as the matrix itself is electrically conductive. Multiple models have been proposed in order to account for the conductive clay minerals $[26,47,48]$. In general, for both clay and clay-free sediments, the resistivity increases with decreasing water content $[49,50]$. As the present investigation focuses on the upper metres of the soil, the water saturation of the soil itself, as well as the groundwater level, has a strong influence on the measured resistivity. This is exemplified in the Provstlund case (described in Section 4) where the soil samples $1 \mathrm{~m}$ bgs in borehole B7, B11 and B13 all were described as clay till but had measured resistivities above $500 \Omega \mathrm{m}$. All the soil samples were from the unsaturated zone located on the highest elevation of the site. The very high resistivities are assumed to result from a very low water saturation of the clay till.

The local and seasonal variations of water content are assumed to be the most important obstacle in interpreting the geophysical mapping and hence hamper a regional translation from resistivity into lithology, especially when operating in the upper 1-2 m bgs, where weather conditions have a huge impact on the water saturation of the soil and the presence of groundwater. The geophysical mapping, therefore, cannot stand alone and has to be correlated with soil descriptions from boreholes and infiltration tests covering the different units identified on the site.

\subsection{Resistivities Versus Infiltration Tests}

In Figure 3, resistivity is plotted against the percolation rates. A simple linear regression test has been conducted on the data. With a $p$-value below $0.05\left(5.6 \times 10^{-5}\right)$, we reject the null hypothesis representing uncorrelated parameters. Hence, a significant relationship between resistivity and the percolation rates on a regional scale exists. The linear regression line has an $\mathrm{R}^{2}$ value of 0.11 . Thus, the measured resistivity is only able to explain $11 \%$ of the observed variations in the percolation rates. The relationship between resistivity and percolation rates is therefore considered so weak on a regional scale that in reality no meaningful relationships can be establish. Notice, as the resistivity and percolation rates are plotted as a log-linear using a logarithmic scale on the $\mathrm{x}$-axis, and a linear scale on the y-axis the linear regression line is curving.

\subsection{Lithologies Versus Infiltration Tests}

In Figure 3, a box plot showing the measured 147 percolation rates for various lithologies is presented. The lithologies were derived from boreholes located within $1 \mathrm{~m}$ from the infiltration test or from the soil sample itself. As observed from the box plot, it is possible to assign an infiltration capacity with moderate certainty based on the lithologies, as the Q1 quartiles for sand and sandy till do not overlap with the Q3 quartile for clay till. The sand-dominated units, such as sand and sandy till, have relatively higher percolation rates than the clay-dominated clay till and have median percolation rates of $9.9 \times 10^{-5} \mathrm{~m} / \mathrm{s}$ for sand and $6.5 \times 10^{-5} \mathrm{~m} / \mathrm{s}$ for sandy till, compared to $2.6 \times 10^{-5} \mathrm{~m} / \mathrm{s}$ for clay till.

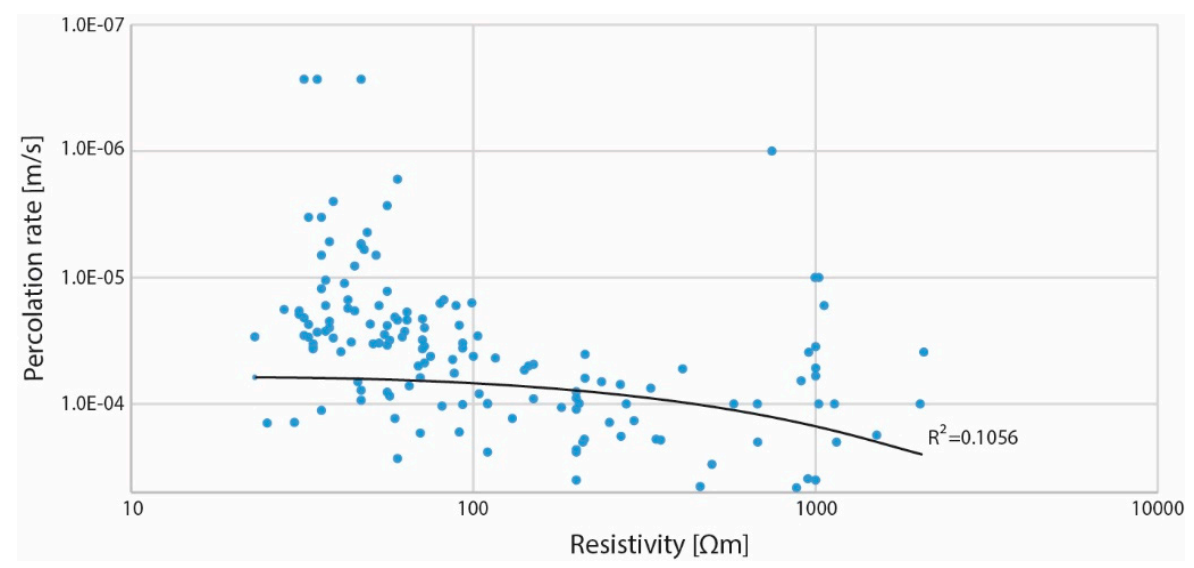

Figure 3. Plot showing the resistivity versus the percolation rate. 
It is important to estimate the infiltration capacity of the different soils, as it will determine the most suitable location for the selected SUDS as well as the expected performance and size of the SUDS solution. As observed in Figure 4, the percolation rate of both sand and clay till varies significantly. For the sand-dominated deposits, a few infiltration test outliers and the presence of fine-grained sand account for the low percolation rates of around $1 \times 10^{-6} \mathrm{~m} / \mathrm{s}$. The percolation rate of clay till varies from $2.7 \times 10^{-7} \mathrm{~m} / \mathrm{s}$ to $2 \times 10^{-4} \mathrm{~m} / \mathrm{s}$. These results are in accordance with the results obtained by Bockhorn et al. [38]. The variation in percolation rates for the clay till is most likely due to soil structure, the $\mathrm{CaCO} 3$ boundary and earthworm burrows. Bockhorn et al. [15] investigated various factors controlling the infiltration capacity of SUDS in clay till and found that fractures, earthworm burrows and structural changes in the soil had a significant effect on the infiltration capacity.

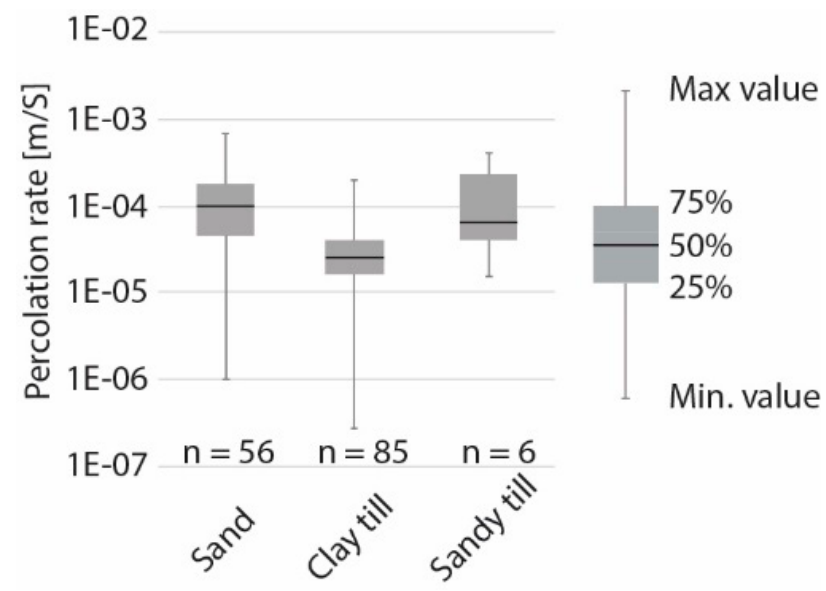

Figure 4. Box plot showing the percolation rates for sand, clay till and sandy till for all investigated areas. $\mathrm{N}$ represents the amount of measurements for each soil type.

\subsection{Resistivities Versus in Situ Vane Tests}

In Figure 5, resistivity is plotted against the undrained shear strength of cohesive soils obtained using the in situ vane tests. A simple linear regression test has been performed on the data. With a $p$-value below $0.05\left(2.3 \times 10^{-3}\right)$, we reject the null hypothesis that there is no relationship between the two variables being studied. Hence, there exists a significant linear regression relationship between resistivity and the undrained shear strength of cohesive soils. The linear regression line has an $R^{2}$ value of only 0.038 . Thus, the measured resistivity is only able to explain $4 \%$ of the observed variations in the undrained shear strength of cohesive soils, implying that the relationship between the resistivity and undrained shear strength of cohesive soils must be very weak on a regional scale, and in reality no meaningful relationships can be establish. Notice, as the resistivity and the undrained shear strength of cohesive soils is plotted as a log-linear using a logarithmic scale on the x-axis, and a linear scale on the $y$-axis the linear regression line is curving. In the literature, other studies have tried to establish a relationship between electrical resistivity and geotechnical data, such as standard penetration test (SPT), dynamic cone penetration test (DCPT), Atterberg limit, triaxial compression, oedometer consolidation as well as the in situ vane test [51-56]. As in this study, they found that the relationships are area-specific, and the results cannot be transferred from one area to another.

As seen from the quantitative analysis, no reliable relationships could be established between resistivity and the percolation rate or the undrained shear strength of cohesive soils on a regional scale. The obtained DUALEM-421S data used in the quantitative analysis has not undergone any data transformation (e.g., been sorted or binned logarithmically) before being used in the statistical analysis which most likely would have improved the $\mathrm{R}^{2}$ values. However, as this study aims to investigate an immediate relationship between the measured DUALEM-421S data and the percolation rate or the undrained shear strength of cohesive soils without the use of a time-consuming and thereby more expensive data transformation process, this has not been conducted in this investigation. 


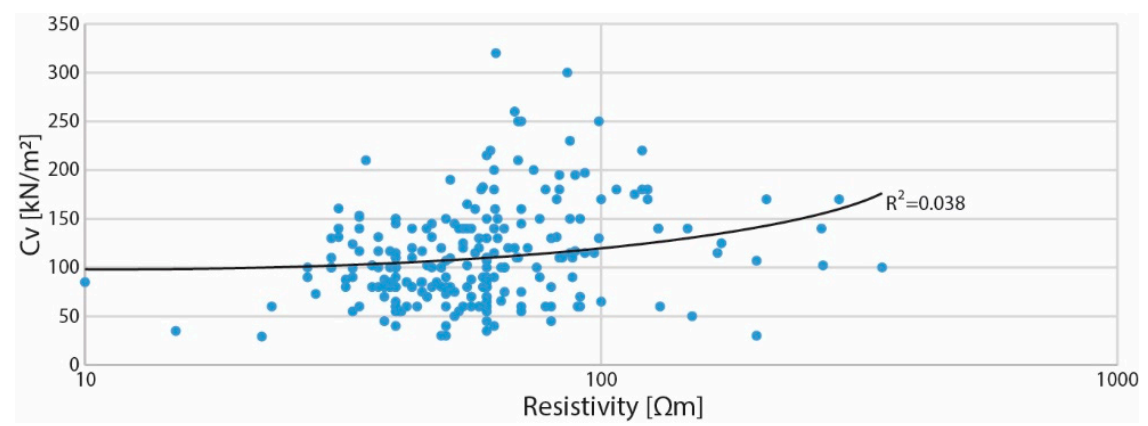

Figure 5. Resistivity plotted against the undrained shear strength of cohesive soils.

Based on the qualitative analysis, the comparison of the lithologies versus resistivities and percolation rates can be estimated with moderate to high certainty on a regional scale. If used with caution, the qualitative findings can be used in the initial investigation phase in order to translate the geophysical mapping into an overall lithology and assign a percolation rate as well as an undrained shear strength of cohesive soils. If more credible relationships are necessary for the urban planners to construct, e.g., potential infiltration planning maps, then site-specific local investigations are needed. This will be exemplified with one case study from Provstlund (no. 21, Figure 1 and Table 1).

\section{Case Study: Provstlund}

The Provstlund site is a 27 ha formerly agricultural area situated about $5 \mathrm{~km}$ northwest of Horsens, Figure 6. In 2017, the site was mapped with DUALEM-421S, resulting in a total of 60,301 measurements. Of that, $4.3 \%$ of the data was removed due to noise or couplings from buried conductors, leaving a total of 57,714 measurements for the inversion. The time span of the geophysical mapping was one day.

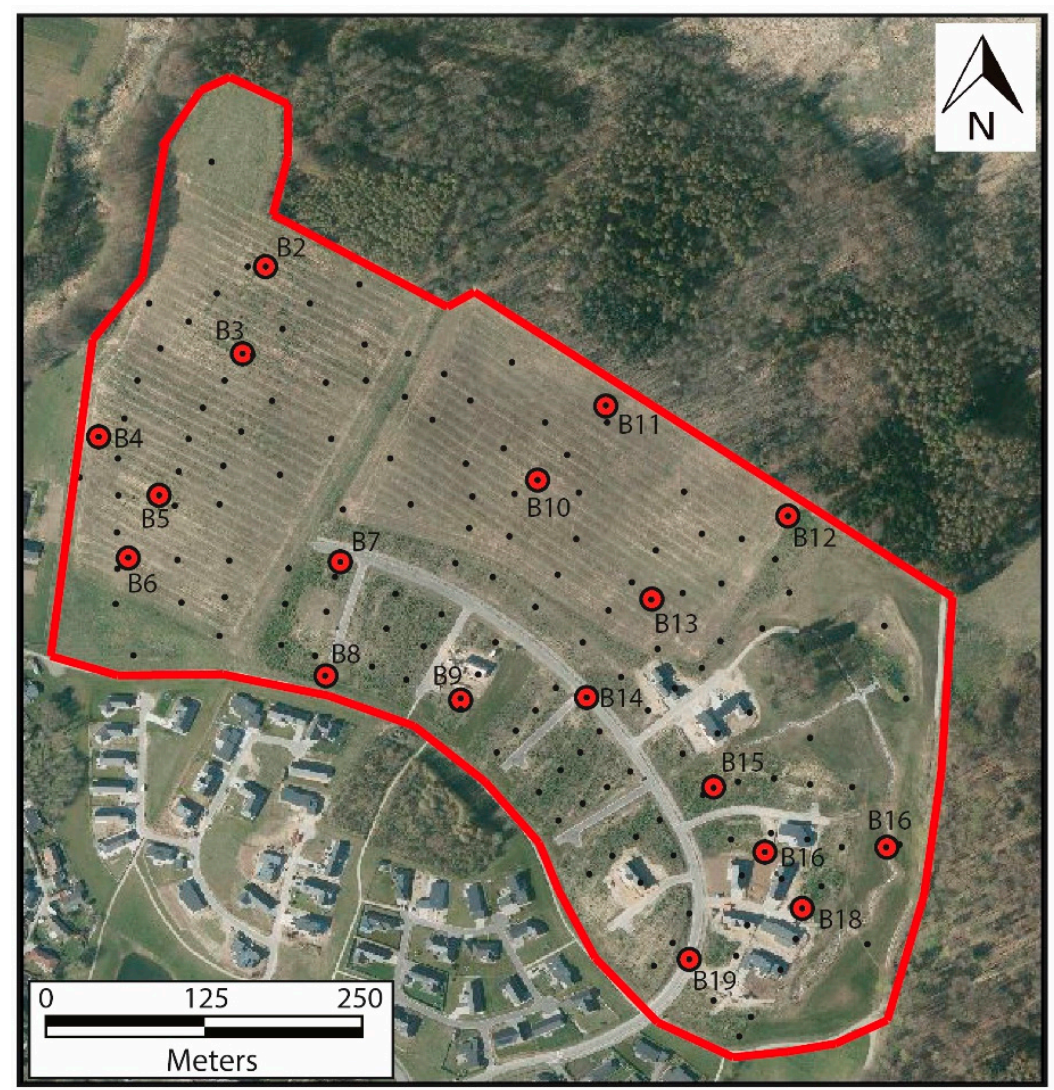

Figure 6. Overview map showing drillings (black dots) and infiltration test (red dots). 
The mean interval resistivity plots from the DUALEM-421S are plotted in Figure 7. From 0 to $3 \mathrm{~m}$ bgs, the interval resistivity plots each represent the calculated mean resistivity within $50 \mathrm{~cm}$ of soil. From 3 to $6 \mathrm{~m}$ bgs, each interval resistivity plot represents $1 \mathrm{~m}$. The calculated mean interval resistivity plots are blinded at the calculated penetration depth (DOI), so the number of data points decreases downwards. At the Provstlund site, the penetration depth varied from 5 to $7 \mathrm{~m}$. The calculated mean resistivity is presented as points, and no kind of interpolation of the calculated values has been made. As observed in Figure 7, high resistances $(>100 \Omega \mathrm{m})$ were generally seen in the upper $1.0 \mathrm{~m}$ in large parts of the area. Smaller areas with medium resistances $(30-60 \Omega \mathrm{m})$ were seen mainly in the north-western and south-eastern parts of the area. The extent of the medium resistivity areas was typically 150 to $200 \mathrm{~m}^{2}$. From 1 to $2 \mathrm{~m}$ bgs, the medium resistivity areas expanded to more continuous and larger areas. The largest areas were observed towards the southeast, central and west. From 1.5 to $2 \mathrm{~m}$ bgs, $1 / 3$ of the area comprised areas with medium resistivities, and 2/3 of the area comprised areas with high resistivities. Larger contiguous high-resistivity areas were seen in the central part of the region as well as in the north-eastern corner and in the north-western and south-western parts of the area. From $2.5 \mathrm{~m}$ bgs to $6 \mathrm{~m}$ bgs, similar resistivity patterns were observed, with half the area comprising of medium resistivity and the other half of high resistivity areas. The high resistivity areas were observed in the north-western, south-western and eastern parts of the area. The north-western and south-western high resistivity areas had the same overall size and shape, whereas the eastern high resistivity area shrank in size with depth.

Within a few days of the geophysical mapping, 18 drillings, each $4 \mathrm{~m}$ deep, 18 infiltration tests and 19 in situ vane tests were performed. The drillings were placed in uniform resistivity zones based on the geophysical mapping results. In the additional geotechnical investigation phase, around three months after the geophysical mapping, 143 drillings ranging in depth from 4 to $6 \mathrm{~m}$ and 141 in situ vane tests were conducted, as shown in Figure 6. Their placement was independent of the results from the geophysical mapping campaign.

In all the drillings, the groundwater level was observed to be situated below the terminus of the drillings, implying that it is located more than $4 \mathrm{~m}$ bgs. Out of the total set of drillings, 159 were described with respect to lithology and groundwater level and in 59 of the drillings the undrained shear strength was obtained. In Figure 8, the box plot showing the minimum, maximum and median values as well as the Q1 and Q3 quartiles for resistivities of various lithologies at $1 \mathrm{~m}$ bgs at Provstlund is plotted. The lithologies were derived from the drillings, and the resistivity was selected from the nearest DUALEM-421S measurement.

As observed from Figure 8, sand and clay till can be distinguished with moderate to high certainty based on their resistivities, as the upper Q3 (75\%) and the lower Q1 (25\%) quartiles do not overlap. On the other hand, it is not possible to clearly distinguish sandy till from either sand or clay till, as their upper Q3 (75\%) and lower Q1 (25\%) quartiles overlap. Thus, sandy till might be misinterpreted as sand or as clay till. The median resistivities were 445,198 and $83 \Omega \mathrm{m}$ for sand, sandy till and clay till, respectively. At the Provstlund site, the differences in median resistivities for sand, sandy till and clay till were $+216,-4$ and $+27 \Omega \mathrm{m}$, respectively, compared to the regional median resistivity. The higher resistivities of sand and clay till at Provstlund were most likely due to low water saturation of the soils and low-lying groundwater level. Hence, the cut-off value between sand and clay till was set to $150 \Omega \mathrm{m}$, compared to the regional scale cut-off value that is between 80 to $100 \Omega \mathrm{m}$. The high difference in cut-off values between Provstlund and the regional value showed that local data sampling was necessary to create reliable translations between resistivities and lithologies. 

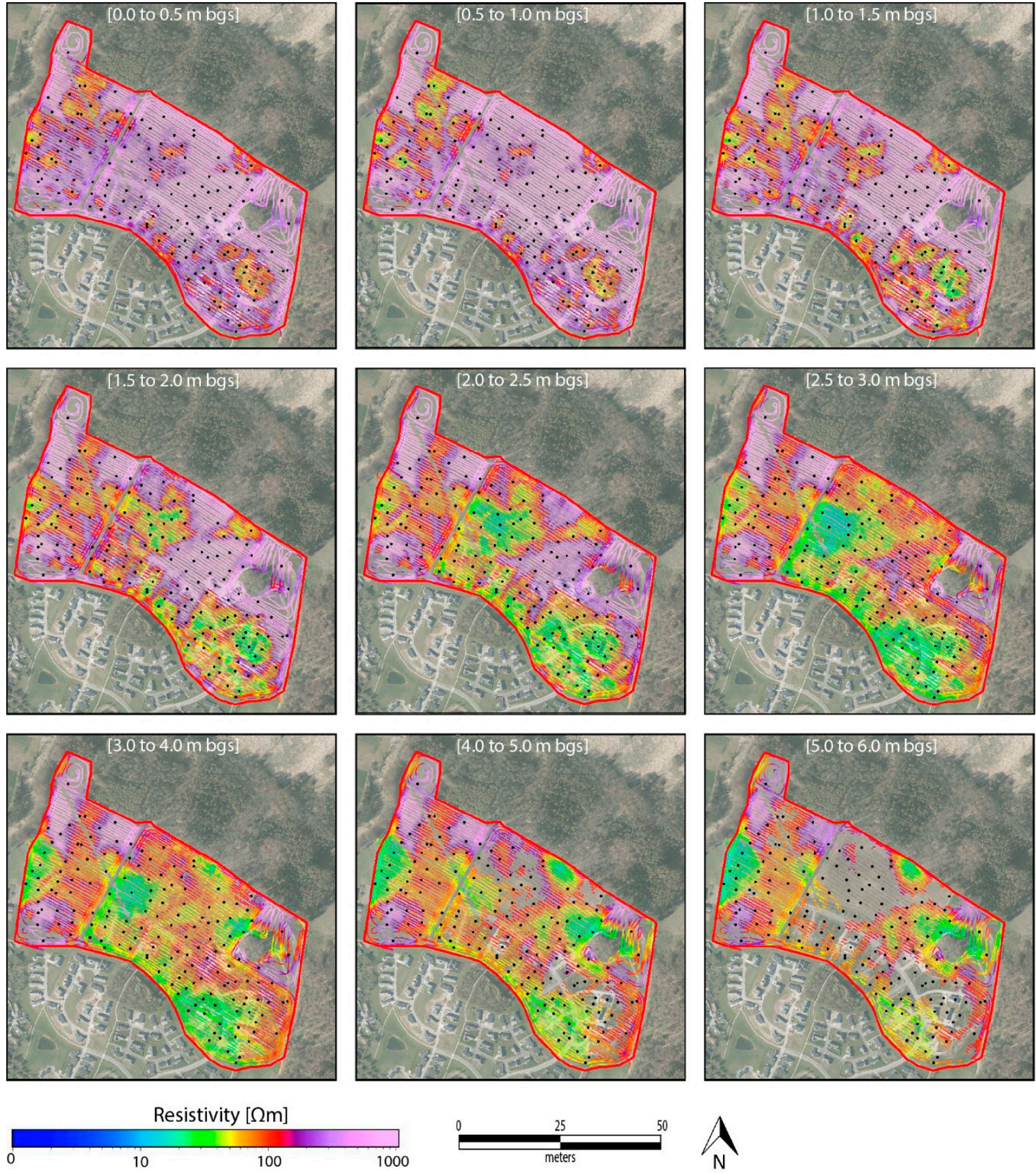

Figure 7. Interval resistivity maps from selected depths. The black dots represent drillings.

To obtain an overview of the hydraulic capacity of the soil layers in the area, 18 infiltration tests were performed (see Figure 6). The infiltration tests were performed next to the boreholes so that the results could be compared with the geological descriptions, as in Table 2. To obtain a representative measurement, the topsoil layer (approx. 0.5 to $1 \mathrm{~m}$ ) was excavated before performing the infiltration tests, so that all tests were made on undisturbed soil. Table 2 shows the results of the infiltration tests and the geophysical mean resistivity values measured in the depth range 0.5 to $1 \mathrm{~m}$, which represented the depth the infiltration tests were performed in. In general, a very good correlation was seen between areas with high resistance, a sandy lithology from the boreholes and high percolation rates spanning from $1 \times 10^{-4} \mathrm{~m} / \mathrm{s}$ to $4 \times 10^{-5} \mathrm{~m} / \mathrm{s}$, Table 2 . However, boreholes 11 and 13 should be mentioned; both showed high resistances but were described as moraine clays and had percolation rates of around 4 to $5 \times 10^{-5} \mathrm{~m} / \mathrm{s}$, which was interpreted as dry moraine clays. The remaining boreholes were all described 
as having moraine clays in the upper $1 \mathrm{~m}$, which correlated well with the low resistances $(30-80 \Omega \mathrm{m})$ and percolation rates spanning from $5 \times 10^{-5} \mathrm{~m} / \mathrm{s}$ to $5 \times 10^{-6} \mathrm{~m} / \mathrm{s}$. All the percolation rates obtained at the Provstlund site are similar to the regional percolation rates (see Figure 4).

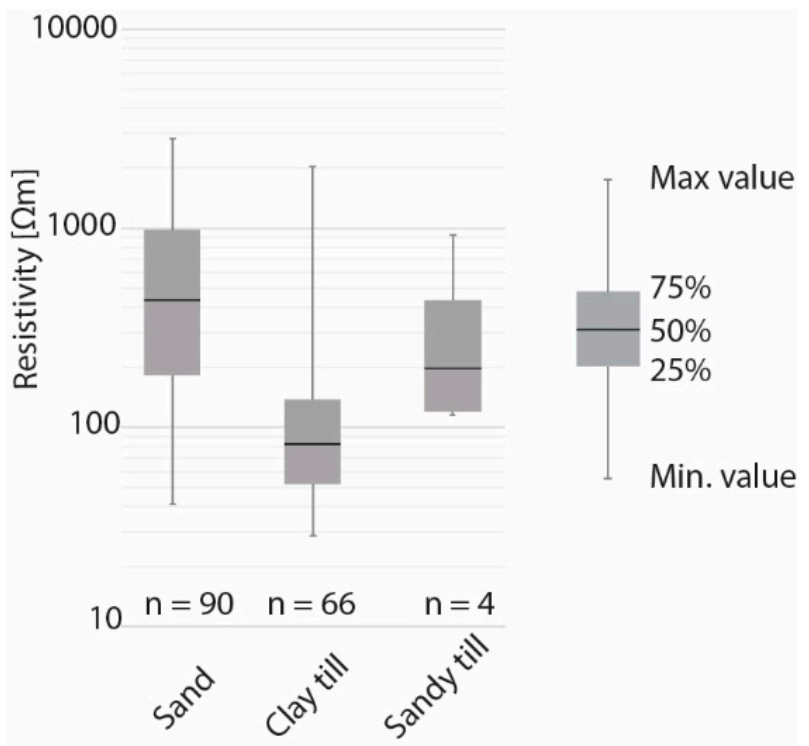

Figure 8. Box plot showing the resistivities within the Provstlund site. $\mathrm{N}$ represents the number of measurements for each soil type.

Table 2. Boreholes, Measured Percolation Rates, Nearest Resistivity and Lithology for the 18 Drillings at the Provstlund Site.

\begin{tabular}{cccc}
\hline Borehole no & $\begin{array}{c}\text { Percolation Rates } \\
(\mathbf{m} / \mathbf{s})\end{array}$ & $\begin{array}{c}\text { Resistivity } \mathbf{1} \mathbf{~ m} \text { bgs } \\
(\mathbf{\Omega m})\end{array}$ & $\begin{array}{c}\text { Lithology } \\
(\mathbf{1} \text { m bgs) }\end{array}$ \\
\hline B2 & $6.67 \times 10^{-5}$ & 40 & Clay till, sandy \\
B3 & $7.78 \times 10^{-5}$ & 38 & Clay till, sandy \\
B4 & $1.23 \times 10^{-5}$ & 36 & Clay till \\
B5 & $4.39 \times 10^{-6}$ & 38 & Clay till \\
B6 & $1.67 \times 10^{-5}$ & 886 & Sand \\
B7 & $7 \times 10^{-5}$ & 541 & Clay till \\
B8 & $3.33 \times 10^{-5}$ & 561 & Sand \\
B9 & $2.96 \times 10^{-5}$ & 64 & Clay till \\
B10 & $3.67 \times 10^{-5}$ & 73 & Clay till \\
B11 & $6.55 \times 10^{-5}$ & 1750 & Clay till, sandy \\
B12 & $2.33 \times 10^{-5}$ & 65 & Clay till \\
B13 & $3.89 \times 10^{-5}$ & 2073 & Clay till \\
B14 & $1.76 \times 10^{-4}$ & 2550 & Sand \\
B15 & $3.33 \times 10^{-5}$ & 93 & Clay till \\
B16 & $2.08 \times 10^{-5}$ & 53 & Clay till \\
B17 & $3.52 \times 10^{-5}$ & 1601 & Sand \\
B18 & $1.79 \times 10^{-5}$ & 50 & Clay till, sandy \\
B19 & $1.50 \times 10^{-5}$ & 102 & Clay till \\
\hline
\end{tabular}

A total of 46 in situ vane tests were conducted in Provstlund in order to achieve the undrained shear strength of cohesive soils. A simple linear regression test was conducted on the data. With a $p$-value above $0.05(0.69)$, we cannot reject the null hypothesis that there is no relationship between the two variables being studied. Hence, at the Provstlund site, we cannot conclude whether or not there is a significant linear relationship between resistivity and the undrained shear strength of cohesive soils. 
Thus, in order to achieve a reliable overview of the undrained shear strength, multiple in situ vane tests need to be conducted.

Based on the geophysical mapping, soil descriptions and infiltration tests, high-resistivity areas can be interpreted as sand-dominated areas having percolation rates spanning $2 \times 10^{-5} \mathrm{~m} / \mathrm{s}$ to $1 \times 10^{-4} \mathrm{~m} / \mathrm{s}$, corresponding to medium to fine-grained sand. Similarly, low resistivity areas can be interpreted as clay-dominated areas with percolation rates between $5 \times 10^{-5} \mathrm{~m} / \mathrm{s}$ to $5 \times 10^{-6} \mathrm{~m} / \mathrm{s}$, corresponding to clay tills. Based on the data, a planning map for the Provstlund site can be created showing areas suitable for the infiltration of surface water, as in Figure 9. The geophysical mapping, soil descriptions from boreholes and infiltration tests provide information on the volume, areal extent and hydraulic properties of various soils, and the groundwater head measurements provide information about the volume of the unsaturated zone. Combining the data enables city planners to construct planning maps with precise estimates of the most suitable areas for infiltration as well as the volume of free space in unsaturated soil for infiltrated water. As observed from Figure 9, the most suitable areas for infiltration are located throughout the Provstlund site, with the biggest continuous areas in the eastern and south-western parts of the site. Medium-sized areas are observed in the northern part of the site and the smallest area in the south. The areas are characterised as having high resistivity areas, boreholes showing sand-dominated soil descriptions, infiltration capacities of $2 \times 10^{-5} \mathrm{~m} / \mathrm{s}$ to $1 \times 10^{-4} \mathrm{~m} / \mathrm{s}$ and a thickness of more than $4 \mathrm{~m}$ in the unsaturated zone.

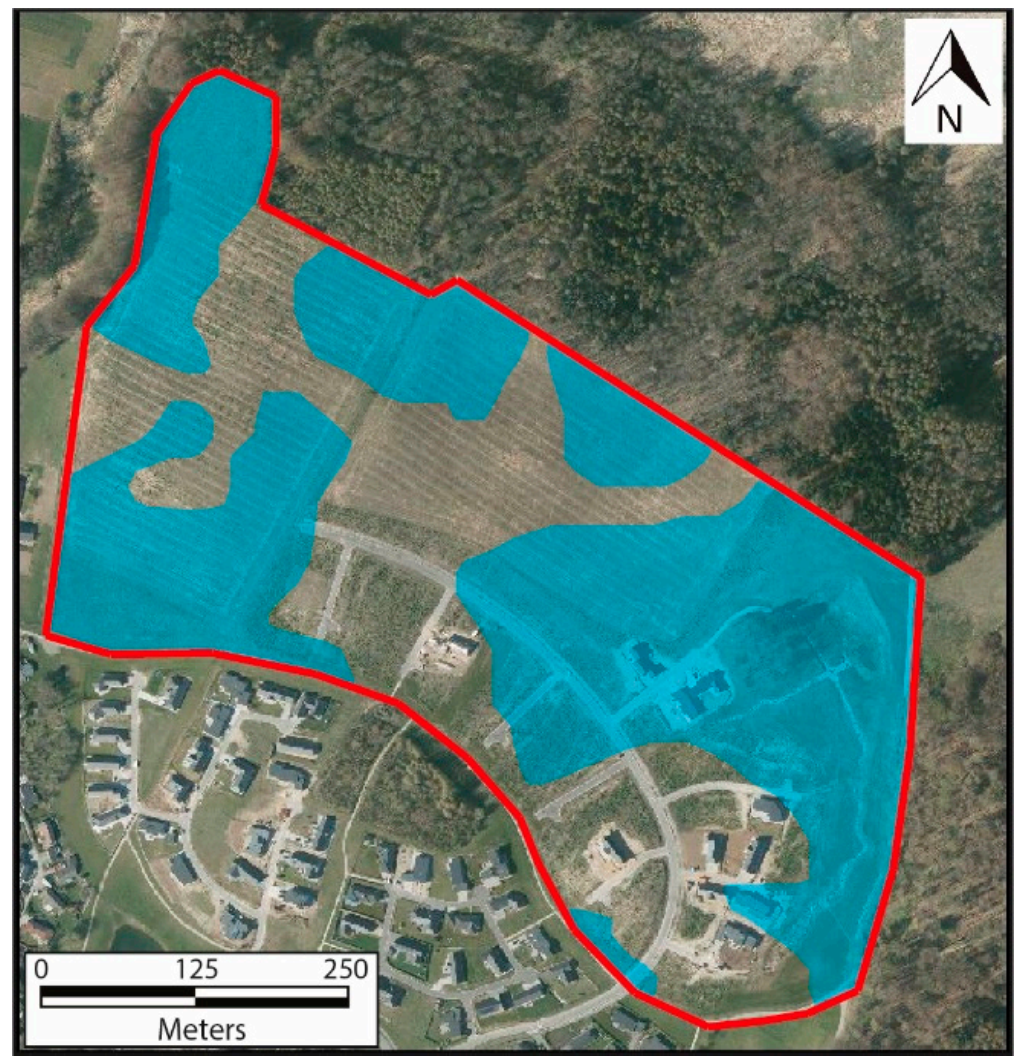

Figure 9. Areas marked with blue are found to be suitable areas for infiltration.

A planning map showing the most suitable areas for infiltration provides authorities with a powerful tool when planning the future urbanisation of the site. The map enables them to organise the areas based on holistic water cycle management, focusing on the best SUDS solution for the area, instead of having the individual citizens handling their own rainwater, creating multiple bad solutions. The best-suited locations for potential infiltration are defined, primarily based on the areal extents of the various soils, their percolation rates and the thickness of the unsaturated zone. 
The DUALEM-421S method has proven to be very useful for producing a comprehensive overview of the horizontal and vertical resistivity distributions of the future urban site. The DUALEM-421S system, depending on site conditions, is able to cover up to 50 to $80 \mathrm{~km}$ in one field day, providing a high-density geophysical mapping of the upper 5 to $10 \mathrm{~m}$ of the subsurface. In this investigation, the DUALEM-421S was able to distinguish clay-dominated sediments, such as clay till and meltwater clay from sand-dominated sediments, such as sand, sandy till and fillings with moderate to a high degree of certainty. This investigation found the regional cut-off value between clay-dominated sediments and sand-dominated sediments to be around 80 to $100 \Omega \mathrm{m}$, which is in accordance with the results from Frederiksen et al., [36] and Barfod et al., [31]. However, as the investigation focuses on the upper meters of the subsurface, the obtained resistivity results are highly dependent on the water saturation of the soil and the groundwater level. This is illustrated by the Provstlund site, where unsaturated sand and clay tills yielded a higher cut-off value of $150 \Omega \mathrm{m}$. Thus, the DUALEM-421S method has to be supplemented with boreholes yielding soil descriptions and groundwater head measurements. Without dense geophysical mapping combined with infiltration tests, boreholes and groundwater head measurements, the planning maps would have been inaccurate, leading to incorrect decisions in the future.

The Provstlund case study illustrates that combining geophysical mapping with boreholes and infiltration tests facilitates the construction of accurate and reliable planning maps. The amount of data necessary for constructing the planning maps is highly dependent on the complexity of the geology and therefore changes from case to case. Typically, with a high-density geophysical mapping campaign with, e.g., DUALEM-421S, the number of boreholes and infiltration tests necessary for constructing the planning maps can be limited, compared to traditional Danish investigation strategies. In the Provstlund case, the strategy of placing 18 boreholes in various resistivity zones yielded sufficient information to construct the planning map with respect to water management. During the traditional geotechnical investigation, a total of 143 additional drillings were conducted, and they did not significantly improve the overall geological knowledge of the site. However, it should be noted that drillings are necessary, as the geophysical mapping cannot substitute the geotechnical data derived during the drilling campaign.

\section{Conclusions}

Based on 1315 ha of high-density electromagnetic (DUALEM-421S) data, detailed lithological soil descriptions of 614 boreholes, 153 infiltration tests and 250 in situ vane tests, regional relationships between resistivity and lithology and percolation rates and undrained shear strength of cohesive soils were tested at a depth of $1 \mathrm{~m}$ bgs.

This investigation revealed that the DUALEM-421S method is able to map the upper 5 to $10 \mathrm{~m}$ of the subsurface in very high detail, yielding a precise overview of the vertical and horizontal resistivity distribution.

Based on the qualitative tests a translation from resistivity to lithology as well as a translation from lithologies to percolation rates could be conducted with a moderate to high degree of certainty. We found a regional cut-off value separating sand-dominated deposits from clay-dominated deposits is between 80 to $100 \Omega \mathrm{m}$ and a regional median percolation rate for sand and clay till to be $9.9 \times 10^{-5} \mathrm{~m} / \mathrm{s}$ and $2.6 \times 10^{-5} \mathrm{~m} / \mathrm{s}$, respectively.

The quantitative results showed a very weak relationship between the resistivity and percolation rates and the resistivity and the undrained shear strength of cohesive soils and in reality no meaningful relationships can be establish.

The regional qualitative results were tested on the Provstlund case-study area in order to illustrate how combining geophysical mapping with boreholes and infiltration tests can support the construction of accurate and reliable planning maps showing the most suitable locations for infiltration. The Provstlund case study finds that the overall regional results only should be applied in the initial screening phase in order to translate the geophysical results into lithology units and assign them with 
percolation rates. Hereafter site-specific investigations are necessary to directly estimate lithology, percolation rates and undrained shear strength of cohesive soils due to the differences in the physical properties of the soil from site to site. The largest uncertainties originate from the variation in soil saturation and groundwater level, causing resistivity ranges for each lithology to widen.

The presented findings reveal that geophysical mapping in combination with lithological descriptions, infiltration tests and measurements of groundwater levels yield the basis for the construction of detailed planning maps showing the most suitable locations for infiltration. These maps contain valuable information for city planners regarding future developments and reduce uncertainty. They provide unique information by which a SUDS in a specific area may be restricted or precluded, as well as information about the expected performance of the SUDS.

Funding: This research project was funded by EU LIFE, grant number LIFE15 IPC/DK/000006-C2C CC".

Acknowledgments: The author is grateful to the municipalities of Aarhus, Favrskov, Hedensted, Horsens, Skanderborg and Viborg and the companies Rambøll and DMR for providing the data and their assistance during the practical and analytical work. I would also like to thank my students for helping me carry out the field and laboratory work. I would also like to thank Anna Bondo Medhus and Karl Woldum Tordrup, who provided helpful comments and suggestions that improved the paper. Finally, the author would like to thank the journal reviewers whose constructive and relevant comments significantly improved the paper.

Conflicts of Interest: The author declares no conflict of interest and the funders had no role in the design of the study, collection, analyses, or interpretation of data, writing of the manuscript or in the decision to publish the results.

\section{References}

1. Department of Economic and Social Affairs, Population Division. World Urbanization Prospects: The 2018 Revision; ST/ESA/SER.A/420; United Nations: New York, NY, USA, 2019.

2. $\quad$ Langen, P.L.; Boberg, F.; Pedersen, R.A.; Christensen, O.B.; Sørensen, A.; Madsen, M.S.; Olesen, M.; Darholt, M. Klimaatlas_Rapport Danmark; Danmarks Meteorologiske Institut: Copenhagen, Denmark, 2019.

3. Min, S.K.; Zhang, X.; Zwiers, F.W.; Hegerl, G.C. Human Contribution to More-Intense Precipitation Extremes. Nature 2011, 470, 378-381. [CrossRef] [PubMed]

4. Luo, P.; Mu, D.; Xue, H.; Ngo-Duc, T.; Dang-Dinh, K.; Takara, K.; Nover, D.; Schladow, G. Flood Inundation Assessment for the Hanoi Central Area, Vietnam under Historical and Extreme Rainfall Conditions. Sci. Rep. 2018, 8, 1-11. [CrossRef] [PubMed]

5. Economic Losses from Climate-Related Extremes in Europe-European Environment Agency. Available online: https:/www.eea.europa.eu/data-and-maps/indicators/direct-losses-from-weather-disasters-3/ assessment-2 (accessed on 19 October 2020).

6. Scholz, M.; Grabowiecki, P. Review of Permeable Pavement Systems. Build. Environ. 2007, 42, 3830-3836. [CrossRef]

7. Oral, H.V.; Carvalho, P.; Gajewska, M.; Ursino, N.; Masi, F.; van Hullebusch, E.D.; Kazak, J.K.; Exposito, A.; Cipolletta, G.; Andersen, T.R.; et al. A Review of Nature-Based Solutions for Urban Water Management in European Circular Cities: A Critical Assessment Based on Case Studies and Literature. Blue-Green Syst. 2020, 2,112-136. [CrossRef]

8. Ossa-Moreno, J.; Smith, K.M.; Mijic, A. Economic Analysis of Wider Benefits to Facilitate SuDS Uptake in London, UK. Sustain. Cities Soc. 2017, 28, 411-419. [CrossRef]

9. Duffy, A.; Jefferies, C.; Waddell, G.; Shanks, G.; Blackwood, D.; Watkins, A. A Cost Comparison of Traditional Drainage and SUDS in Scotland. Water Sci. Technol. 2008, 57, 1451-1459. [CrossRef]

10. Webber, J.L.; Fu, G.; Butler, D. Comparing Cost-effectiveness of Surface Water Flood Management Interventions in a UK Catchment. J. Flood Risk Manag. 2019, 12, e12523. [CrossRef]

11. Fenner, R. Spatial Evaluation of Multiple Benefits to Encourage Multi-Functional Design of Sustainable Drainage in Blue-Green Cities. Water 2017, 9, 953. [CrossRef]

12. Wentworth, J. Urban Green Infrastructure and Ecosystem Services. Houses of Parliament, Parliamentary Office of Science \& Technology. POST Brief Number 26. July 2017. Available online: https://post.parliament. uk/research-briefings/post-pb-0026/ (accessed on 6 November 2020). 
13. Charlesworth, S.M. A Review of the Adaptation and Mitigation of Global Climate Change Using Sustainable Drainage in Cities. J. Water Clim. Chang. 2010, 1, 165-180. [CrossRef]

14. Fredericia, J. Saturated Hydraulic Conductivity of Clayey Tills and the Role of Fractures. Hydrol. Res. 1990, 21, 119-132. [CrossRef]

15. Bockhorn, B.; Klint, K.E.S.; Locatelli, L.; Park, Y.J.; Binning, P.J.; Sudicky, E.; Jensen, M.B. Factors Affecting the Hydraulic Performance of Infiltration Based SUDS in Clay. Urban Water J. 2017, 14, 125-133. [CrossRef]

16. Dearden, R.A.; Marchant, A.; Royse, K. Development of a Suitability Map for Infiltration Sustainable Drainage Systems (SuDS). Environ. Earth Sci. 2013, 70, 2587-2602. [CrossRef]

17. Loke, M.H.; Chambers, J.E.; Rucker, D.F.; Kuras, O.; Wilkinson, P.B. Recent Developments in the Direct-Current Geoelectrical Imaging Method. J. Appl. Geophys. 2013, 95, 135-156. [CrossRef]

18. Ozcep, F.; Ozcep, T. Geophysical Analysis of the Soils for Civil (Geotechnical) Engineering and Urban Planning Purposes: Some Case Histories from Turkey. Int. J. Phys. Sci. 2011, 6, 1169-1195. [CrossRef]

19. Pellerin, L. Applications of Electrical and Electromagnetic Methods for Environmental and Geotechnical Investigations. Surv. Geophys. 2002, 23, 101-132. [CrossRef]

20. Revil, A.; Karaoulis, M.; Johnson, T.; Kemna, A. Review: Some Low-Frequency Electrical Methods for Subsurface Characterization and Monitoring in Hydrogeology. Hydrogeol. J. 2012, 20, 617-658. [CrossRef]

21. Maurya, P.K.; Christiansen, A.V.; Pedersen, J.; Auken, E. High Resolution 3D Subsurface Mapping Using a Towed Transient Electromagnetic System-TTEM: Case Studies. Near Surf. Geophys. 2020, 18, 249-259. [CrossRef]

22. Jørgensen, F.; Lykke-Andersen, H.; Sandersen, P.B.E.; Auken, E.; Nørmark, E. Geophysical Investigations of Buried Quaternary Valleys in Denmark: An Integrated Application of Transient Electromagnetic Soundings, Reflection Seismic Surveys and Exploratory Drillings. J. Appl. Geophys. 2003, 53, 215-228. [CrossRef]

23. Andersen, T.R.; Poulsen, S.E.; Thomsen, P.; Havas, K. Geological Characterization in Urban Areas Based on Geophysical Mapping: A Case Study from Horsens, Denmark. J. Appl. Geophys. 2017, 150, 338-349. [CrossRef]

24. Price, S.J.; Terrington, R.L.; Busby, J.; Bricker, S.; Berry, T. 3D Ground-Use Optimisation for Sustainable Urban Development Planning: A Case-Study from Earls Court, London, UK. Tunn. Undergr. Space Technol. 2018, 81, 144-164. [CrossRef]

25. Archie, G.E. The Electrical Resistivity Log as an Aid in Determining Some Reservoir Characteristics. Soc. Pet. Eng. 1942, 146, 54-62. [CrossRef]

26. Lima, O.A.L.; Sharma, M. A Grain Conductivity Approach to Shaly Sandstones. Geophysics 1990, 55, 1347-1356. [CrossRef]

27. Beamish, D. The Bedrock Electrical Conductivity Map of the UK. J. Appl. Geophys. 2013, 96, 87-97. [CrossRef]

28. Pozdnyakova, L.; Pozdnyakov, A.; Zhang, R. Application of Geophysical Methods to Evaluate Hydrology and Soil Properties in Urban Areas. Urban Water 2001, 3, 205-216. [CrossRef]

29. Samouëlian, A.; Cousin, I.; Tabbagh, A.; Bruand, A.; Richard, G. Electrical Resistivity Survey in Soil Science: A Review. Soil Tillage Res. 2005, 83, 173-193. [CrossRef]

30. Thomsen, R.; Søndergaard, V.H.; Sørensen, K.I. Hydrogeological Mapping as a Basis for Establishing Site-Specific Groundwater Protection Zones in Denmark. Hydrogeol. J. 2004, 12, 550-562. [CrossRef]

31. Barfod, A.A.S.; Møller, I.; Christiansen, A.V. Compiling a National Resistivity Atlas of Denmark Based on Airborne and Ground-Based Transient Electromagnetic Data. J. Appl. Geophys. 2016, 134, 199-209. [CrossRef]

32. Doolittle, J.A.; Brevik, E.C. The Use of Electromagnetic Induction Techniques in Soils Studies. Geoderma 2014, 223-225, 33-45. [CrossRef]

33. Triantafilis, J.; Santos, F.A.A.M. Electromagnetic Conductivity Imaging (EMCI) of Soil Using a DUALEM-421 and Inversion Modelling Software (EM4Soil). Geoderma 2013, 211-212, 28-38. [CrossRef]

34. Klint, K.E.S.; Møller, I.; Maurya, P.K.; Christiansen, A.V. Optimising Geological Mapping of Glacial Deposits Using High-Resolution Electromagnetic Induction Data. Geol. Surv. Den. Greenl. Bull. 2017, 38, 9-12. [CrossRef]

35. Brogi, C.; Huisman, J.A.; Pätzold, S.; von Hebel, C.; Weihermüller, L.; Kaufmann, M.S.; van der Kruk, J.; Vereecken, H. Large-Scale Soil Mapping Using Multi-Configuration EMI and Supervised Image Classification. Geoderma 2019, 335, 133-148. [CrossRef]

36. Frederiksen, R.R.; Christiansen, A.V.; Christensen, S.; Rasmussen, K.R. A Direct Comparison of EMI Data and Borehole Data on a 1000 Ha Data Set. Geoderma 2017, 303, 188-195. [CrossRef]

37. Bockhorn, B.; Møller, I.; Klint, K.E.S.; Jensen, M.B. Geoelectrical Mapping for Improved Performance of SUDS in Clay Tills. Environ. Earth Sci. 2015, 74, 5263-5273. [CrossRef] 
38. Bockhorn, B.; Klint, K.E.S.; Jensen, M.B.; Møller, I. Use of Geological Mapping Tools to Improve the Hydraulic Performance of SuDS. Water Sci. Technol. 2015, 71, 1492-1499. [CrossRef]

39. Houmark-Nielsen, M. Pleistocene Stratigraphy and Glacial History of the Central Part of Denmark. Bull. Geol. Soc. Den. 1987, 36, 1-189.

40. Christiansen, A.V.; Auken, E. A Global Measure for Depth of Investigation. Geophysics 2012, 77, WB171-WB177. [CrossRef]

41. Auken, E.; Viezzoli, A.; Christensen, A. A Single Software for Processing, Inversion, and Presentation of AEM Data of Different Systems: The Aarhus Workbench. ASEG Ext. Abstr. 2009, 2009(1), 1-5. [CrossRef]

42. Auken, E.; Christiansen, A.V.; Kirkegaard, C.; Fiandaca, G.; Schamper, C.; Behroozmand, A.A.; Binley, A.; Nielsen, E.; Effersø, F.; Christensen, N.B.; et al. An Overview of a Highly Versatile Forward and Stable Inverse Algorithm for Airborne, Ground-Based and Borehole Electromagnetic and Electric Data. Explor. Geophys. 2015, 46, 223-235. [CrossRef]

43. Dansk Ingeniørforening (IDA). Norm for Fundering, DS 415, 3rd ed.; Teknisk forlag: Copenhagen, Denmark, 1984.

44. Danish Technological Institute. Nedsivning af Regnvand i Faskiner-Udførelse af InfiltrationstestTeknologisk Institut. Available online: https://www.teknologisk.dk/nedsivning-af-regnvand-i-faskiner/ udfoerelse-af-infiltrationstest/16402,2 (accessed on 28 September 2020).

45. Danish Geotechnical Society-Field Committee. Reference Test Procedure for Field Vane Tests; 1999. Available online: https://danskgeotekniskforening.dk/sites/default/files/pdf/referenceblade/Fieldvanetest-dk. pdf (accessed on 6 November 2020).

46. Blæsild, P.; Granfeldt, J. Statistics with Applications in Biology and Geology; Chapman and Hall/CRC: New York, NY, USA, 2002.

47. Waxman, M.H.; Smits, L.J.M. Electrical Conductivities in Oil-Bearing Shaly Sands. Soc. Pet. Eng. J. 1968, 8, 107-122. [CrossRef]

48. Shevnin, V.; Mousatov, A.; Ryjov, A.; Delgado-Rodriquez, O. Estimation of Clay Content in Soil Based on Resistivity Modelling and Laboratory Measurements. Geophys. Prospect. 2007, 55, 265-275. [CrossRef]

49. Bhatt, S.; Jain, P.K. Correlation between Electrical Resistivity and Water Content of Sand-A Statistical Approach. Am. Int. J. Res. Sci. Technol. Eng. Math. 2014, 6, 115-121.

50. Russell, E.J.F.; Barker, R.D. Electrical Properties of Clay in Relation to Moisture Loss. Near Surf. Geophys. 2010, 8, 173-180. [CrossRef]

51. Akinlabi, I.A.; Adeyemi, G.O. Determination of Empirical Relations between Geoelectrical Data and Geotechnical Parameters in Foundation Studies for a Proposed Earth Dam. Pac. J. Sci. Technol. 2014, 15, 278-287.

52. Braga, A.C.O.; Malagutti, F.W.; Dourado, J.C.; Chang, H.K. Correlation of Electrical Resistivity and Induced Polarization Data with Geotechnical Survey Standard Penetration Test Measurements. J. Environ. Eng. Geophys. 1999, 4, 123-130. [CrossRef]

53. Cosenza, P.; Marmet, E.; Rejiba, F.; Cui, Y.J.; Tabbagh, A.; Charlery, Y. Correlations between Geotechnical and Electrical Data: A Case Study at Garchy in France. J. Appl. Geophys. 2006, 60, 165-178. [CrossRef]

54. Devi, A.; Israil, M.; Anbalagan, R.; Gupta, P.K. Subsurface Soil Characterization Using Geoelectrical and Geotechnical Investigations at a Bridge Site in Uttarakhand Himalayan Region. J. Appl. Geophys. 2017, 144, 78-85. [CrossRef]

55. Sudha, K.; Israil, M.; Mittal, S.; Rai, J. Soil Characterization Using Electrical Resistivity Tomography and Geotechnical Investigations. J. Appl. Geophys. 2009, 67, 74-79. [CrossRef]

56. Andersen, T.R.; Poulsen, S.E.; Pagola, M.A.; Medhus, A.B. Geophysical Mapping and 3D Geological Modelling to Support Urban Planning: A Case Study from Vejle, Denmark. J. Appl. Geophys. 2020, 180, 104130. [CrossRef]

Publisher's Note: MDPI stays neutral with regard to jurisdictional claims in published maps and institutional affiliations. 